\title{
Comparison of diagnostic accuracy between periapical and panoramic radiographs and cone beam computed tomography in measuring the periapical area of teeth scheduled for periapical surgery. A cross-sectional study
}

\author{
Amparo Ramis-Alario 1, Beatriz Tarazona-Alvarez ${ }^{2}$, Juan Cervera-Ballester ${ }^{1}$, David Soto-Peñaloza ${ }^{1}$, Miguel \\ Peñarrocha-Diago ${ }^{3}$, David Peñarrocha-Oltra ${ }^{4}$, María Peñarrocha-Diago ${ }^{5}$
}

\footnotetext{
${ }^{1}$ Professor of Master in Oral Surgery and Implantology, Faculty of Medicine and Dentistry, University of Valencia, Valencia, Spain ${ }^{2}$ Assistant Professor of Orthodontics, Master in Orthodontics, Faculty of Medicine and Dentistry, University of Valencia, Valencia, Spain

${ }^{3}$ Chairman of Oral Surgery. Director of the Master in Oral Surgery and Implantology, Faculty of Medicine and Dentistry, University of Valencia, Valencia, Spain

${ }^{4}$ Assistant Postdoctoral Professor of Oral Surgery, Master in Oral Surgery and Implantology, Faculty of Medicine and Dentistry, University of Valencia, Valencia, Spain

${ }^{5}$ Full Professor of Oral Surgery, Master in Oral Surgery and Implantology, Faculty of Medicine and Dentistry, University of Valencia, Valencia, Spain
}

Correspondence:

C/Gasco Oliag n ${ }^{\circ}$ 1. Clinica Odontologica

Facultad de Medicina y Odontologia

Universidad de Valencia

46010 Valencia (Spain)

beatriz.tarazona@uv.es

\begin{abstract}
Ramis-Alario A, Tarazona-Alvarez B, Cervera-Ballester J, Soto-Peñaloza D, Peñarrocha-Diago M, Peñarrocha-Oltra D, Peñarrocha-Diago MA. Comparison of diagnostic accuracy between periapical and panoramic radiographs and cone beam computed tomography in measuring the periapical area of teeth scheduled for periapical surgery. A cross-sectional study. J Clin Exp Dent. 2019;11(8):e732-8.

http://www.medicinaoral.com/odo/volumenes/v11i8/jcedv11i8p732.pdf
\end{abstract}

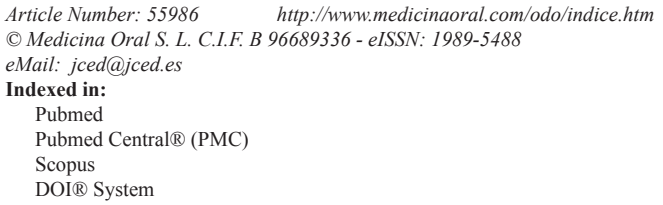

\begin{abstract}
Background: The aim of the study was compare the sensitivity and measurements obtained from teeth with apical lesions scheduled for periapical surgery using three different diagnostic methods: periapical radiography (Gendex Expert DC), panoramic radiography (Planmeca ${ }^{\circledR}$ Promax 3D Classic) and cone beam computed tomography (CBCT) (Planmeca ${ }^{\circledR}$ Promax 3D Classic).

Study design: This cross-sectional study involved 35 patients (45 teeth) scheduled for periapical surgery in which periapical radiographs, panoramic radiographs and CBCT scans had been obtained. The images were used to analyze the maximum vertical and horizontal dimension and the resulting areas of the periapical lesions based on the three diagnostic methods.

Results: The two-dimensional techniques (periapical radiography and panoramic radiography) yielded a sensitivity of $82 \%$ versus $100 \%$ in the case of CBCT. The mean vertical dimension of the apical areas was $5.48 \mathrm{~mm}$ with periapical radiography and $5.04 \mathrm{~mm}$ with panoramic radiography - the difference with respect to CBCT being statistically significant $(6.36 \mathrm{~mm}$ for the coronal sections). There were no significant differences among the three techniques in terms of horizontal dimension $(p>0.05)$ or lesion area.
\end{abstract}


Conclusions: The sensitivity of periapical radiolucencies detected using CBCT was significantly greater than with the two-dimensional imaging techniques. Significant differences between the latter and CBCT were only observed in the case of the vertical measurements.

Key words: Periapical lesion, apicoectomy, CBCT, periapical radiography, panoramic radiography.

\section{Introduction}

Apical periodontitis is defined as radiolucency associated to the most apical portion of the root of the tooth and measuring at least twice as wide as the normal periodontal width (1). Such lesions are usually accompanied by bone reabsorption, producing a radiographically identifiable periapical area (2).

Apical periodontitis is monitored based on the clinical and radiographic findings. Radiological assessment is essential for the successful and timely diagnosis, since the condition may be asymptomatic $(3,4)$. The prevalence of apical periodontitis is greater in teeth that have been subjected to endodontic treatment (5), being observed in $36 \%$ of all endodontically treated teeth, depending on the population studied (6).

In relation to the radiological study of periapical lesions, a number of authors have shown cone beam computed tomography (CBCT) to offer greater diagnostic sensitivity than periapical radiography $(4,7)$. The fact of being able to see the images in three dimensions improves and advances the diagnosis (8). However, the few studies that have compared the dimensions of the periapical radiolucency using two-dimensional radiography and CBCT have reported no significant differences between the two techniques $(9,10)$.

On the other hand, despite the widespread use of panoramic radiography in dental clinics, no studies have established quantitative comparisons of the areas obtained with two-dimensional radiography and CBCT. Furthermore, both bidimensional radiographs, have important limitations, as they are overlays of certain anatomical structures, the fact that lesions limited to cancellous bone can go unnoticed, until the cortical bone is eroded or neither these lesions will be detected until the bone mineral loss reaches $30-50 \%$ (1).

Studying the previous size of the periapical lesion is important because it is strongly related to the prognosis of the apical surgery. Higher rates of successful are guaranteed with lesions minors than $5 \mathrm{~mm}$, versus higher lesions, hence the importance of studying the size before apical surgery $(11,12)$.

In keeping with the above-mentioned observations, the present study compares: (i) the sensitivity to detect apical lesions in teeth scheduled for periapical surgery and (ii) the size of these lesions, using three different radiographic diagnostic techniques: periapical radiography, panoramic radiography and $\mathrm{CBCT}$. The null hypothesis is that there is no difference neither in the sensibility nor in none of the measurements between the three methods.

\section{Material and Methods}

-Study design and participants

This study was conformed to STROBE guidelines for cross-sectional human observational study (13). The study was carried out in our Dental School (Valencia University, Valencia, Spain) between March 2015 and March 2017. All patients scheduled for periapical surgery were included. Written informed consent was obtained from all participants, and the study was approved by the local Ethics Committee (Reference: H1490891777899). -Selection of cases

Patients with teeth scheduled for periapical surgery, with the obtainment of periapical radiographs, panoramic radiographs and CBCT scans. The exclusion criteria were: images of deficient quality (incomplete visualization of the roots or cortical components) and images with the three techniques obtained in a period of time superior to two months.

-Radiographic examination

The digital periapical radiographs were obtained with the Gendex Expert DC system (Gendex Dental Systems, Hatfield, USA), using the Vista Scan radiological sensor (Dürr Dental AG, Bietigheim-Bissingen, Germany) (4 x $3 \mathrm{~cm}$ ) with the following exposure parameters: $65 \mathrm{kV}, 7$ $\mathrm{mA}$, and times from 0.08 to 0.18 , depending on the tooth evaluated. All the periapical radiographs were obtained using a parallel technique (Super-Bite, Kerr). The digital images were processed and filed using DBSWIN software (Dürr Dental). The panoramic radiographs were obtained with a Planmeca ${ }^{\circledR}$ system (Promax 3D Classic, Helsinki, Finland), using the Planmeca Romexis program for image processing. The exposure parameters were: $68 \mathrm{kV}, 10 \mathrm{~mA}, 19$ seconds.

The CBCT scans were obtained with a Planmeca ${ }^{\circledR}$ system (Promax 3D Classic, Helsinki, Finland), using the following operating parameters: $90 \mathrm{kV}, 10 \mathrm{~mA}, 15 \mathrm{se}-$ conds for $180^{\circ}$ rotation, and a voxel size of $0.15 \mathrm{~mm}$. The field of view (FOV) of the detector panel was $40 \mathrm{x}$ $40 \mathrm{~mm}$. Planmeca Romexis Viewer software was used to process the CBCT images. Slice thickness was 0.20 $\mathrm{mm}$. For each tooth the sections were modified to align the root axis with the vertical plane in the coronal and sagittal views.

The CBCT scans had been requested to precisely eva- 
luate the anatomical structures affected and the endodontic conditions of the teeth, with a view to performing periapical surgery, and were not obtained as a routine study - thereby complying with the ALARA (As Low As Reasonably Achievable) criterion. The images were evaluated by two blinded examiners (both certified oral surgeons, J.C. and A.R.) not related to the treatment and follow-up of the patients.

-Calibration of examiners

Cone beam computed tomography images were used for calibration and evaluation of inter-examiner accuracy, measuring the distance from the apex of the mesial root of the first mandibular molar to the upper margin of the mandibular canal (14). Ten random measurements were obtained by both examiners, yielding a difference between them of $0.14 \mathrm{~mm}$ per image (range $0.0-0.28 \mathrm{~mm}$ ). The level of agreement between reviewers is obtained through de intraclass correlation coeficient (ICC) and interpreted according the Landhis and Koch scale (15) . -Evaluation of images

In the global study, each measurement was made by the two examiners, with calculation of the average of both measurements. This was the value subsequently used in the data analysis, except in those cases where the two measurements differed by more than $0.2 \mathrm{~mm}$. In such cases a third measurement was made jointly by both examiners (14). The measurements were made in three sessions spaced one week apart. In each session one-third of the images obtained with the different radiographic techniques were evaluated on a random basis (7).

-Linear and area measurements

The two-dimensional (2D) radiographs and CBCT scans were displayed on a Full HD monitor with a resolution of 1920 x 1080 pixels in a dimly lit room. The periapical lesions were measured as follows: Vertical measurements: the maximum vertical dimension (in $\mathrm{mm}$ ) of the area was recorded. Horizontal measurements: the maximum dimension (in $\mathrm{mm}$ ) perpendicular to the previously obtained vertical measurement was recorded.

The same measurement protocol was used for periapical radiography (Fig. 1), panoramic radiography (Fig. 2) and CBCT (Fig. 3). In the latter technique the measurements were obtained from the sagittal and coronal sections. The corresponding area was calculated as a rectangle (vertical measurement multiplied by horizontal measurement), according to a previous study (9). The examiners were able to modify size, brightness and contrast of the images of all three techniques.

-Statistical analysis

Inter-examiner agreement was assessed by contrasting the normal distribution of the differences in measurements using the Kolmogorov-Smirnov test, with calculation of the coefficient of variation (CV) and the intraclass correlation coefficient (ICC). The Student t-test for dependent samples was used to compare the

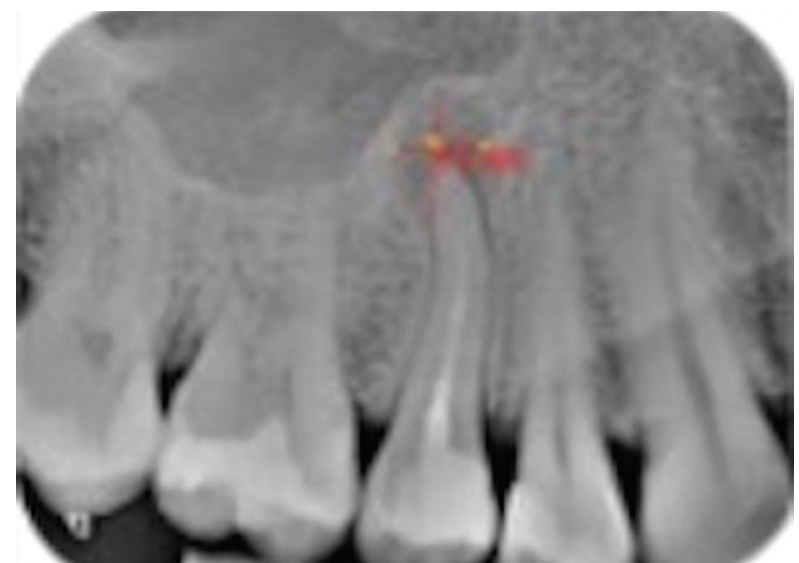

Fig. 1: Vertical and horizontal measurements obtained by periapical radiography.

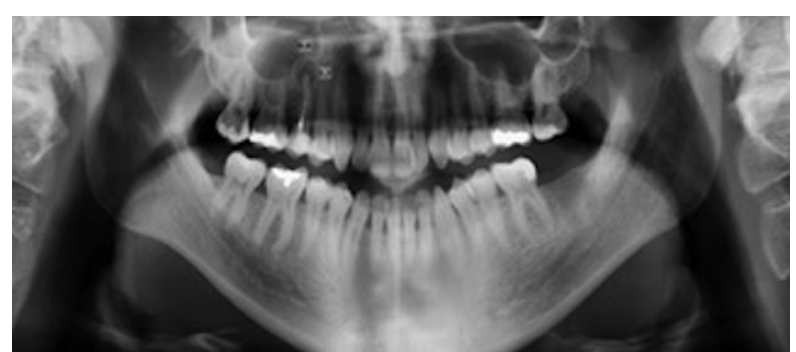

Fig. 2: Panoramic radiograph with the measurements made on the radiolucent area of tooth 15 .

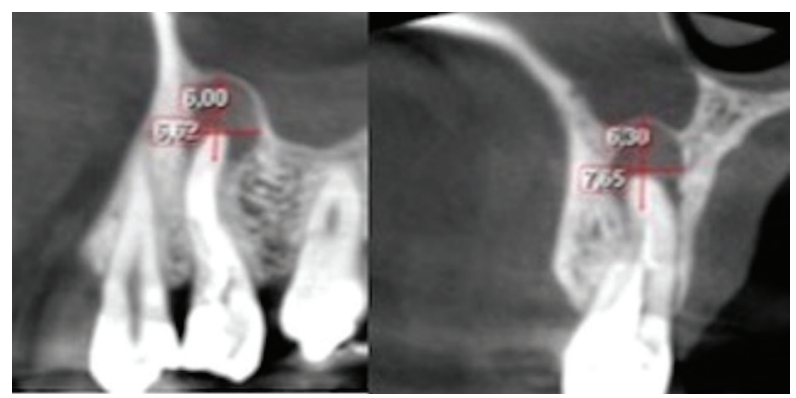

Fig. 3: Sagittal (A) and coronal (B) sections used to obtain the measurements of the periapical area of tooth 15 .

diagnostic accuracy of the three radiological techniques. The Mann-Whitney U-test was used to assess the impact of patient gender upon lesion size, while the Spearman nonlinear correlation coefficient was used to evaluate the influence of age. The level of statistical significance was defined as $5 \%(\alpha=0.05)$. The statistical analysis was conducted using statistical program R (Version R 3.5.1).

\section{Results}

-Sample characteristics and descriptive data The initial sample size consisted of 82 patients, of which 47 were excluded after application of the inclusion and 
exclusion criteria. Patients excluded from the study, with reasons were:

1. Patients with periapical or panoramic radiographs, or CBCT scans, not allowing full visualization of the roots and cortical component of the affected teeth $(\mathrm{n}=29)$.

2. Poor image quality $(n=4)$.

3. Time intervals among the three radiographic studies $>$ 2 months $(\mathrm{n}=6)$.

4. Images taken after the apicectomy $(n=8)$.

The final study sample therefore consisted of 35 patients (45 teeth): 18 males and 17 females, with a mean age of 47 years (range 19-74). The upper incisors were the teeth most frequently affected by periapical disease. The distribution of the teeth is shown in Table 1. periapical radiographs because the distal root was not available on the image, so the sample size is different in this method with regard to the other two. There were no significant differences between the two-dimensional techniques (periapical radiography and panoramic radiography), though significant differences were observed in the vertical measurements between the two-dimensional techniques and $\mathrm{CBCT}$, with higher values when the latter technique was used $(p<0.05)$ (Table 2$)$.

-Horizontal measurements

With regard to the horizontal measurements, the mean values were $4.80 \mathrm{~mm}$ in the case of the periapical radiographs $(n=44, S D \pm 3.43)$ and 5.01 in the case of the panoramic radiographs $(n=45, S D \pm 3.91)$. In the case of

Table 1: Description of the study sample.

\begin{tabular}{|c|c|}
\hline Study variable & Descriptive statistics \\
\hline Sample size & 35 patients (45 periapical areas) \\
\hline Gender & 18 males (51.4\%) and 17 females (48.6\%) \\
\hline Age & 47 years (19-74) \\
\hline Affected teeth: & $15(33.3 \%)$ \\
\hline Upper incisors & $4(8.8 \%)$ \\
\hline Lower incisors & $2(4.4 \%)$ \\
\hline Upper canines & $1(2.2 \%)$ \\
\hline Lower canines & $8(17.8 \%)$ \\
\hline Upper premolars & $3(6.6 \%)$ \\
\hline Lower premolars & $5(11 \%)$ \\
\hline Upper molars & $7(15.5 \%)$ \\
\hline Lower molars &
\end{tabular}

-Detection of periapical areas

The conventional two-dimensional techniques (periapical radiography and panoramic radiography) both showed a sensitivity of $82 \%$. Of the 45 periapical areas, 8 were not detected by either technique: two corresponded to the anterior sector (incisors and canines) and 6 to the posterior sector (premolars and molars). In percentage terms, the two-dimensional techniques failed to register $4.5 \%$ of the anterior lesions and $13.5 \%$ of the posterior lesions. In contrast, CBCT registered all 45 radiolucent areas. Inter-examiner agreement was almost perfect, with $\mathrm{CV}<3 \%$ and ICC $>0.99$ in all cases.

-Vertical measurements of periapical areas

The mean vertical measurement of the apical area was found to be $5.48 \mathrm{~mm}$ with periapical radiography $(\mathrm{n}=44$, $\mathrm{SD} \pm 3.93$ ) and $5.04 \mathrm{~mm}$ with panoramic radiography $(\mathrm{n}=45, \mathrm{SD} \pm 3.61 \mathrm{~mm})$. The results in the case of CBCT were $6.36 \mathrm{~mm}$ in the coronal sections $(\mathrm{n}=45, \mathrm{SD} \pm 3.65)$ and $6.38 \mathrm{~mm}$ in the sagittal sections $(\mathrm{n}=45, \mathrm{SD} \pm 3.45)$. There was a lower molar which wasn't measured on
CBCT the values were $5.63 \mathrm{~mm}$ in the coronal sections $(\mathrm{n}=45, \mathrm{SD} \pm 2.95)$ and $5.10 \mathrm{~mm}$ in the sagittal sections $(\mathrm{n}=44, \mathrm{SD} \pm 2.26)$. No significant differences were observed on comparing the different radiographic techniques: all three were therefore considered to offer similar results in relation to the horizontal measurements $(p>0.05)$ (Table 3).

-Area of periapical bone defects

With regard to the calculation of lesion area from the vertical and horizontal measurements, the results were $37.33 \mathrm{~mm} 2$ for the periapical radiographs $(\mathrm{n}=44$, $\mathrm{SD} \pm 44.49)$ and $36.37 \mathrm{~mm} 2$ for the panoramic radiographs $(\mathrm{n}=45, \mathrm{SD} \pm 47.63)$. In the case of CBCT the area was $44.76 \mathrm{~mm} 2$ in the coronal sections $(\mathrm{n}=45, \mathrm{SD} \pm 49.32)$ and $36.59 \mathrm{~mm} 2$ in the sagittal sections $(\mathrm{n}=44, \mathrm{SD} \pm 29.41)$. Likewise in this case there were no significant differences among the different radiographic techniques: all three were therefore considered to offer similar results in relation to the area measurements (Table 4). The sample size differs from one unit between the different methods, 
Table 2: Difference in measurements (mean and standard deviation [SD]), 95\% confidence interval (95\%CI), t-test for dependent samples ( $p$-value) referred to the vertical dimension (height) among the different radiographic techniques.

\begin{tabular}{|c|c|c|c|c|c|}
\hline & \multicolumn{2}{|c|}{$\begin{array}{c}\text { Difference between } \\
\text { measurements }\end{array}$} & \multicolumn{2}{c|}{$\begin{array}{c}\text { 95\%CI for the } \\
\text { difference }\end{array}$} & \multirow{2}{*}{$\begin{array}{c}P \text {-value } \\
\end{array}$} \\
\hline Rean & SD & $\begin{array}{c}\text { Lower } \\
\text { limit }\end{array}$ & $\begin{array}{c}\text { Upper } \\
\text { limit }\end{array}$ & \\
\hline Rx PERIAPICAL - CBCT coronal & -0.89 & 1.97 & -1.49 & -0.29 & $0.005^{*}$ \\
\hline Rx PANORAMIC - CBCT coronal & -1.31 & 2.75 & -2.20 & -0.52 & $0.003^{*}$ \\
\hline Rx PERIAPICAL - CBCT sagittal & -0.90 & 1.91 & -1.48 & -0.32 & $0.003^{*}$ \\
\hline Rx PANORAMIC - CBCT sagittal & -1.34 & 2.66 & -2.19 & -0.56 & $0.002^{*}$ \\
\hline
\end{tabular}

Table 3: Difference in measurements (mean and standard deviation [SD]), 95\% confidence interval (95\%CI), t-test for dependent samples ( $p$ value) referred to the horizontal dimension (width) among the different radiographic techniques.

\begin{tabular}{|c|c|c|c|c|c|}
\hline & $\begin{array}{c}\text { Difference between } \\
\text { measurements }\end{array}$ & \multicolumn{2}{|c|}{ 95\%CI for the difference } & \multirow{2}{*}{ Upalue } \\
\hline & Mean & SD & Lower limit & Upper limit \\
\hline Rx PERIAPICAL - Rx PANORAMIC & -0.23 & 3.36 & -1.25 & 0.79 & 0.654 \\
\hline Rx PERIAPICAL - CBCT coronal & -0.83 & 2.37 & -1.55 & -0.11 & 0.024 \\
\hline Rx PANORAMIC - CBCT coronal & -0.62 & 3.37 & -1.63 & 0.39 & 0.224 \\
\hline Rx PERIAPICAL - CBCT sagittal & -0.40 & 2.78 & -1.26 & 0.46 & 0.351 \\
\hline Rx PANORAMIC - CBCT sagittal & -0.36 & 3.58 & -1.45 & 0.73 & 0.507 \\
\hline
\end{tabular}

Table 4: Difference in measurements (mean and standard deviation [SD]), 95\% confidence interval (95\%CI), t-test for dependent samples ( $p$ value) referred to lesion area among the different radiographic techniques.

\begin{tabular}{|c|c|c|c|c|c|}
\hline & \multicolumn{2}{|c|}{$\begin{array}{l}\text { Difference between } \\
\text { measurements }\end{array}$} & \multicolumn{2}{|c|}{$95 \% \mathrm{CI}$ for the difference } & \multirow[t]{2}{*}{$P$-value } \\
\hline & Mean & SD & Lower limit & Upper limit & \\
\hline Rx PERIAPICAL - Rx PANORAMIC & 0.76 & 30.15 & -8.40 & 9.93 & 0.868 \\
\hline Rx PERIAPICAL - CBCT coronal & -7.71 & 19.57 & -13.7 & -1.77 & 0.012 \\
\hline Rx PANORAMIC - CBCT coronal & -8.39 & 31.51 & -17.8 & 1.08 & 0.081 \\
\hline Rx PERIAPICAL - CBCT sagittal & -1.87 & 28.47 & -10.63 & 6.89 & 0.669 \\
\hline Rx PANORAMIC - CBCT sagittal & -4.82 & 33.98 & -15.2 & 5.51 & 0.352 \\
\hline
\end{tabular}

because there was an area, due to its size, in periapical radiography and in sagittal sections it couldn't be measured, as its margin was not observed completely so vertical and/or horizontal measure couldn't be registered. Lastly, no significant associations were found between lesion area and patient age or gender.

\section{Discussion}

The present study compared the three radiodiagnostic techniques currently used for the measurement and analysis of radiolucencies produced by periapical infection. Specifically, we compared the different vertical and ho- rizontal measurements and areas obtained with the three imaging techniques, and assessed their diagnostic validity and the possible influence of other associated factors such as patient gender and age.

-Sensitivity of three methods

Is well known that $\mathrm{CBCT}$ sensitivity for the prevalence of periapical radiolucencies was $100 \%(4,16)$. The findings of the present study are in agreement with the above-mentioned trend. However, the prevalence decreased to $82 \%$ when using the two-dimensional radiographic techniques (periapical radiography and panoramic radiography). The failure rate in identifying periapical lesions 
with these techniques in posterior and anterior teeth was $13.5 \%$ and $4.5 \%$, respectively. Liang et al. (17) recorded a similar percentage of $5 \%$ in anterior teeth with periapical radiography, thus coinciding

with our own observation that anterior sector lesions are more easily visualized than posterior lesions. No significant associations were found between lesion area and patient age or gender.

The literature offers similar data $(14,16)$, with a higher periapical lesion non-visualization rate associated to two-dimensional imaging techniques. Lesions close to the maxillary sinus are very likely to go undetected with two-dimensional methods, due to overlapping - this situation being even more probable in the case of the upper second molars (18). Furthermore, CBCT is able to identify possible oroantral communications, which may be important for the planning and success of surgery.

Only one study to date has assessed sensitivity in the case of panoramic radiography (19), though the reported figure $(28 \%)$ falls far short of our own $82 \%$. The difference may be explained by a number of factors, such as the fact that the mentioned study considered teeth both with and without endodontic treatment; as a result, in the case of a tooth not subjected to endodontic treatment, the examiner might not notice the periapical area in the absence of important coronal destruction.

The results of the present study confirmed that both the vertical and horizontal measurements were comparatively greater with $\mathrm{CBCT}$ than with the two-dimensional techniques, though statistical significance was only reached in the case of the vertical measurements. These findings are consistent with the data found in the literature, which likewise describe $\mathrm{CBCT}$ as being more accurate than periapical radiography $(1,2,7,17,19-24)$ or panoramic radiography $(18,19,25)$. All these studies are limited to the evaluation of the sensitivity of the techniques, and only a few have compared the capacity of the three imaging methods to demonstrate the full extent of the lesions, measuring and comparing the lesion areas $(9,10,26,27)$.

-Radiographic and CBCT measurements

We recorded no significant differences in the vertical measurements of the lesions between the two-dimensional radiographic techniques, though significant differences were observed on comparing these techniques with CBCT. However, Bornstein et al. (2) recorded no significant differences on comparing the maximum diameter of the areas with the different radiological methods (e.g. CBCT and periapical radiography).

Similar findings were reported by Gouveilla et al. (10). This coincides with the observations of all those studies that have examined these associations $(1,28-30)$.

-Limitations

However, some limitations need to be considered, such as the variability of vertical and horizontal magnifica- tion, factors that depends on patient position in panoramic radiographs, as well the position of periapical radiographs, was not taken into account as independent factors on analysis.

The clinical relevance of this study lies in the perspective that is not always affordable for a clinician to acquire a CBCT scan for its private's practice, being this economic aspect or third-party services that suppose an important barrier for its accessibility, in particular in developing countries. Strikingly, this limitation is not proportional with the high demand of root canal treatments and prevalence of periapical lesions in everyday clinical practice. Thus, despite limitations, the results of the present study could be extrapolated to clinical practice for apical lesions diagnostic.

Two dimensional radiographic techniques showed significantly lower sensitivity to detect periapical radiolucencies lesions than CBCT. In relation to the vertical dimension of the apical lesions, significant differences were observed between the conventional two-dimensional techniques and CBCT - the former tending to underestimate vertical height. No differences in horizontal dimension or area were observed, however.

\section{References}

1. Sogur E, Baksi B, Gröndahl H-G, Lomcali G, Sen B. Detectability of chemically induced periapical lesions by limited cone beam computed tomography, intra-oral digital and conventional film radiography. Dentomaxillofacial Radiol. 2009;38:458-64.

2. Bornstein MM, Bingisser AC, Reichart PA, Sendi P, Bosshardt DD, von Arx T. Comparison between Radiographic (2-dimensional and 3-dimensional) and Histologic Findings of Periapical Lesions Treated with Apical Surgery. J Endod. 2015;41:804-11.

3. Leonardi Dutra K, Haas L, Porporatti AL, Flores-Mir C, Nascimento Santos J, Mezzomo LA, et al. Diagnostic Accuracy of Cone-beam Computed Tomography and Conventional Radiography on Apical Periodontitis: A Systematic Review and Meta-analysis. J Endod. 2016;42:356-64.

4. Patel S, Wilson R, Dawood A, Foschi F, Mannocci F. The detection of periapical pathosis using digital periapical radiography and cone beam computed tomography - Part 2: a 1-year post-treatment follow-up. Int Endod J. 2012;45:711-23.

5. Jiménez-Pinzón A, Segura-Egea JJ, Poyato-Ferrera M, Velasco-Ortega E, Ríos-Santos J V. Prevalence of apical periodontitis and frequency of root-filled teeth in an adult Spanish population. Int Endod J. 2004;37:167-73.

6. Pak JG, Fayazi S, White SN. Prevalence of Periapical Radiolucency and Root Canal Treatment: A Systematic Review of Cross-sectional Studies. J Endod. 2012;38:1170-6.

7. Abella F, Patel S, Durán-Sindreu F, Mercadé M, Bueno R, Roig M. An evaluation of the periapical status of teeth with necrotic pulps using periapical radiography and cone-beam computed tomography. Int Endod J. 2014;47:387-96.

8. Nair MK, Nair UP. Digital and Advanced Imaging in Endodontics: A Review. J Endod. 2007;33:1-6.

9. Christiansen R, Kirkevang L-L, Gotfredsen E, Wenzel A. Periapical radiography and cone beam computed tomography for assessment of the periapical bone defect 1 week and 12 months after root-end resection. Dentomaxillofac Radio. 2009;38:531-6.

10. Jorge ÉG, Tanomaru-Filho M, Guerreiro-Tanomaru JM, Reis JM, Spin-Neto R, Gonçalves M. Periapical repair following endodontic surgery: two- and three-dimensional imaging evaluation methods. Braz Dent J. 2015;26:69-74. 
11. Peñarrocha M, Martí E, García B, Gay C. Relationship of Periapical Lesion Radiologic Size, Apical Resection, and Retrograde Filling With the Prognosis of Periapical Surgery. J Oral Maxillofac Surg. 2007;65:1526-9.

12. von Arx T, Peñarrocha M, Jensen S. Prognostic Factors in Apical Surgery with Root-end Filling: A Meta-analysis. J Endod. 2010;36:957-73.

13. von Elm E, Altman DG, Egger M, Pocock SJ, Gøtzsche PC, Vandenbroucke JP. The Strengthening the Reporting of Observational Studies in Epidemiology (STROBE) Statement: Guidelines for reporting observational studies. Int J Surg. 2014;12:1495-9.

14. Bornstein MM, Lauber R, Sendi P, von Arx T. Comparison of Periapical Radiography and Limited Cone-Beam Computed Tomography in Mandibular Molars for Analysis of Anatomical Landmarks before Apical Surgery. J Endod. 2011;37:151-7.

15. Landis JR, Koch GG. An application of hierarchical kappa-type statistics in the assessment of majority agreement among multiple observers. Biometrics. 1977;33:363-74.

16. Velvart P, Hecker H, Tillinger G. Detection of the apical lesion and the mandibular canal in conventional radiography and computed tomography. Oral Surgery, Oral Med Oral Pathol Oral Radiol Endodontology. 2001;92:682-8.

17. Liang YH, Jiang L, Gao XJ, Shemesh H, Wesselink PR, Wu MK. Detection and measurement of artificial periapical lesions by cone-beam computed tomography. Int Endod J. 2014;47:332-8.

18. Gargari M, Ottria L, Nezzo M, Neroni L, Fanucci E. Cone Beam $\mathrm{CT}$ use in the pre-prosthetic evaluation of endodontically treated of the rear maxilla. Oral Implantol (Rome). 2012;5:42-6.

19. Estrela C, Bueno MR, Leles CR, Azevedo B, Azevedo JR. Accuracy of Cone Beam Computed Tomography and Panoramic and Periapical Radiography for Detection of Apical Periodontitis. J Endod. 2008;34:273-9.

20. Davies A, Patel S, Foschi F, Andiappan M, Mitchell PJ, Mannocci F. The detection of periapical pathoses using digital periapical radiography and cone beam computed tomography in endodontically retreated teeth - part 2: a 1 year post-treatment follow-up. Int Endod J. 2016;49:623-35.

21. Liang YH, Li G, Wesselink PR, Wu MK. Endodontic Outcome Predictors Identified with Periapical Radiographs and Cone-beam Computed Tomography Scans. J Endod. 2011;37:326-31.

22. Kim S. Endodontic Application of Cone-Beam Computed Tomography in South Korea. J Endod. 2012;38:153-7.

23. Pope O, Sathorn C, Parashos P. A Comparative Investigation of Cone-beam Computed Tomography and Periapical Radiography in the Diagnosis of a Healthy Periapex. J Endod. 2014;40:360-5. https://doi. org/10.1016/j.joen.2013.10.003

24. Ee J, Fayad MI, Johnson BR. Comparison of Endodontic Diagnosis and Treatment Planning Decisions Using Cone-beam Volumetric Tomography Versus Periapical Radiography. J Endod. 2014;40:910-6. 25. Pigg M, List T, Petersson K, Lindh C, Petersson A. Diagnostic yield of conventional radiographic and cone-beam computed tomographic images in patients with atypical odontalgia. Int Endod J. 2011;44:1092-101.

26. López FU, Kopper PMP, Cucco C, Della Bona A, Figueiredo JAP de, Vier-Pelisser FV. Accuracy of Cone-beam Computed Tomography and Periapical Radiography in Apical Periodontitis Diagnosis. J Endod. 2014;40:2057-60.

27. Ordinola-Zapata R, Bramante CM, Duarte MH, Ramos Fernandes LMPS, Camargo EJ, de Moraes IG, et al. The influence of cone-beam computed tomography and periapical radiographic evaluation on the assessment of periapical bone destruction in dog's teeth. Oral Surgery, Oral Med Oral Pathol Oral Radiol Endodontology. 2011;112:272-9.

28. Nur Kurt S, Erdogan ur, Evlice B, Yoldas O. Outcomes of Periradicular Surgery of Maxillary First Molars Using a Vestibular Approach: A Prospective, Clinical Study With One Year of Follow-Up. J Oral Maxillofac Surg. 2014;72:1049-61.

29. von Arx T, Roux E, Bürgin W. Treatment decisions in 330 cases referred for apical surgery. J Endod. 2014;40:187-91.
30. Lemagner F, Maret D, Peters OA, Arias A, Coudrais E, Georgelin-Gurgel M. Prevalence of Apical Bone Defects and Evaluation of Associated Factors Detected with Cone-beam Computed Tomographic Images. J Endod. 2015;41:1043-7.

Acknowledgements

The authors deny any conflicts of interest related to this study.

\section{Conflicts of interest}

All authors confirm that there are no known conflicts of interest associated with this publication and there has been no significant financial support for this work that could have influenced its outcome. 